\title{
Improved selectivity of an engineered multi-product terpene synthase $\uparrow$
}

\author{
Ryan Lauchli, $\$ \S$ Julia Pitzer, $\$$ Rebekah Z. Kitto, Karolina Z. Kalbarczyk and \\ Kersten S. Rabe*ब
}

Mutation of the sesquiterpene synthase Cop2 was conducted with a high-throughput screen for the cyclization activity using a non-natural substrate. A mutant of Cop2 was identified that contained three amino acid substitutions. This mutant, 17H2, converted the natural substrate FPP into germacrene D-4-ol with $77 \%$ selectivity. This selectivity is in contrast to that of the parent enzyme in which germacrene D-4-ol is produced as $29 \%$ and $\alpha$-cadinol is produced as $46 \%$ of the product mixture. The mutations were shown to each contribute to this selectivity, and a homology model suggested that the mutations lie near to the active site though would be unlikely to be targeted for mutation by rational methods. Kinetic comparisons show that $17 \mathrm{H} 2$ maintains a $k_{\text {cat }} / K_{M}$ of $0.62 \mathrm{mM}^{-1} \mathrm{~s}^{-1}$, which is nearly identical to that of the parent Cop2, which had a $k_{\text {cat }} / K_{\mathrm{M}}$ of $0.58 \mathrm{mM}^{-1} \mathrm{~s}^{-1}$.

Received 3rd March 2014

Accepted 9th April 2014

DOI: $10.1039 / c 4 o b 00479 e$

www.rsc.org/obc screen the large number of mutants generated via random mutagenesis, many of which may be misfolded. Furthermore, even when focusing on mutations in the active site or those identified using homology or structural information, the resulting mutants frequently suffer from decreased activity. For example, mutation to the $\mathrm{H}-\alpha 1$ loop of sesquiterpene synthases Cop4 and Cop6 severely impeded the kinetic behavior of these enzymes. ${ }^{9}$ In another example, thermostabilization of the sesquiterpene tobacco epi-aristolochene synthase caused lowered activity in the thermostabilized mutant. ${ }^{8}$ It is a general problem in terpene synthase engineering that mutations in these enzymes often lead to decreased activity.

We are aware of only one previous study using a highthroughput assay to screen terpene synthase mutants that were engineered for altered product formation. ${ }^{4}$ The assay identified terpene synthase mutants with an increased likelihood of correct folding, yet it provided no information on the cyclization activity of these mutants. Therefore, significant effort was expended in a secondary screen to determine which mutants maintained the activity.

We recently disclosed a high-throughput assay for the cyclization activity in sesquiterpene synthases and subjected a highly selective fungal terpene synthase to two rounds of directed evolution. ${ }^{13}$ In the course of these two rounds, in which the enzyme was evolved for thermostability, the high selectivity of the enzyme for its native product was maintained and there was no apparent loss of activity. In the current study, we applied random mutagenesis to a multi-product terpene synthase using this high-throughput assay to identify a mutant that maintained the wild-type activity while concurrently changing and improving the product selectivity of the enzyme. 


\section{Results}

Cop2 is a multi-product sesquiterpene synthase from Coprinus cinereus, and no crystal structure is known for this enzyme. ${ }^{14}$ The product composition formed from Cop2 includes products believed to result from a number of distinct cyclization chemistries.

Error-prone PCR (epPCR) was used to create random point mutations in the Cop2 gene. The Cop2 mutants thus generated were expressed as a library in E. coli. The library consisted of about 3000 clones with an average error rate of 1.4 base pair (bp) mutations per gene. This library was screened for the cyclization activity using the high-throughput screen we previously developed. The screen relies upon the usage of a surrogate substrate (S1), which contains a vinyl methyl ether moiety at the head of the molecule in place of the dimethylalkene moiety found in the natural substrate, FPP. Terpene synthase-mediated cyclization of S1 is measured by methanol release using an enzyme-coupled colorimetric readout. An active mutant denoted by $17 \mathrm{H} 2$ was identified in this library with comparable activity to the parent as measured by this screen.

The mutant of Cop 2 denoted by $17 \mathrm{H} 2$ was shown to be a triple mutant containing mutations L59H, T65A and S310Y. The reactions of both Cop 2 and $17 \mathrm{H} 2$ with the natural substrate FPP were investigated by GC-MS measurements. Reactions of purified enzymes were run in buffer in vials with an overlayer of hexanes. Though previous headspace analysis of Cop2 reactions in cell culture led to the proposal that Cop2 is a germacrene A synthase, ${ }^{14}$ analysis of the terpenes extracted into overlayers showed that this enzyme generates a mixture of products with $\alpha$-cadinol and germacrene D-4-ol present in the largest amounts. Because $\alpha$-cadinol and germacrene D-4-ol are alcohols rather than hydrocarbons (like germacrene A), they were not proportionally represented by headspace analysis because they have both lower vapor pressure and increased solubility in the water layer. Scheme 1 shows a portion of the proposed reaction mechanism for the formation of these two products. No single product comprises more than $50 \%$ of the product mixture, and Cop2 is therefore a multi-product sesquiterpene synthase. In contrast, the triple mutant 17H2 generates a much more selective product mixture as shown in Fig. 1. This mixture is comprised of $77 \%$ of germacrene D-4-ol, and no $\alpha$-cadinol is produced. Thus, the product selectivity was significantly improved.

We measured the activity of $17 \mathrm{H} 2$ on FPP by GC measurements. Kinetic studies on both $17 \mathrm{H} 2$ and Cop2 were estimated using FPP as the substrate, and $K_{\mathrm{m}}$ values were determined assuming Michaelis-Menten kinetics to be $25.5 \mu \mathrm{M}$ for Cop2 and $22.6 \mu \mathrm{M}$ for $17 \mathrm{H} 2$. The $k_{\text {cat }}$ values of $0.015 \mathrm{~s}^{-1}$ and $0.014 \mathrm{~s}^{-1}$ for Cop2 and $17 \mathrm{H} 2$, respectively, were also similar. Consequently, the $k_{\text {cat }} / K_{\mathrm{m}}$ values of $0.58 \mathrm{mM}^{-1} \mathrm{~s}^{-1}$ and $0.62 \mathrm{mM}^{-1} \mathrm{~s}^{-1}$ were nearly identical and show that the mutant retained the activity of the parent (see Table 1). Therefore, screening with a surrogate substrate for active enzymes gave a useful approximation of the activity on the native substrate, FPP.

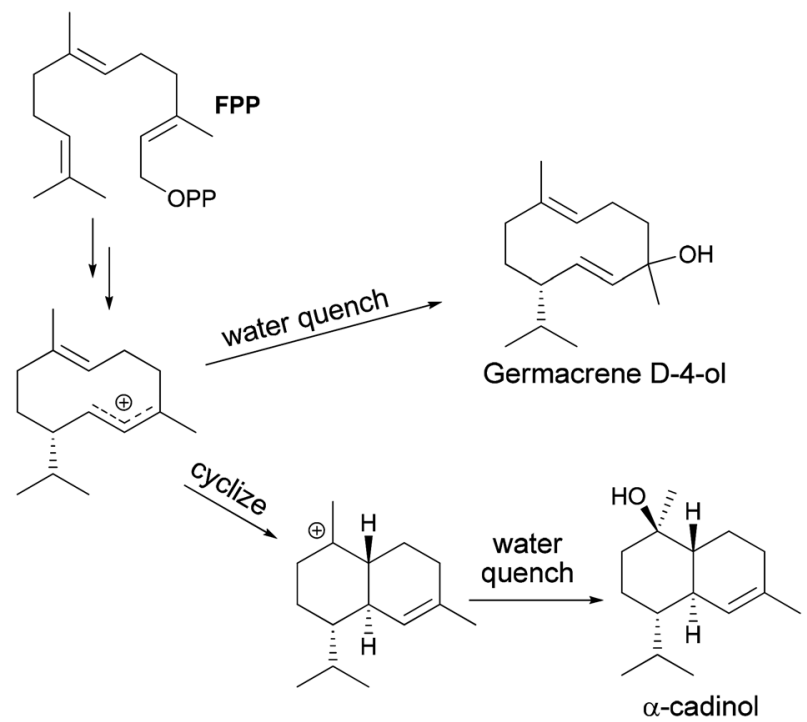

Scheme 1 Proposed formation of the two major products from FPP catalyzed by Cop2.

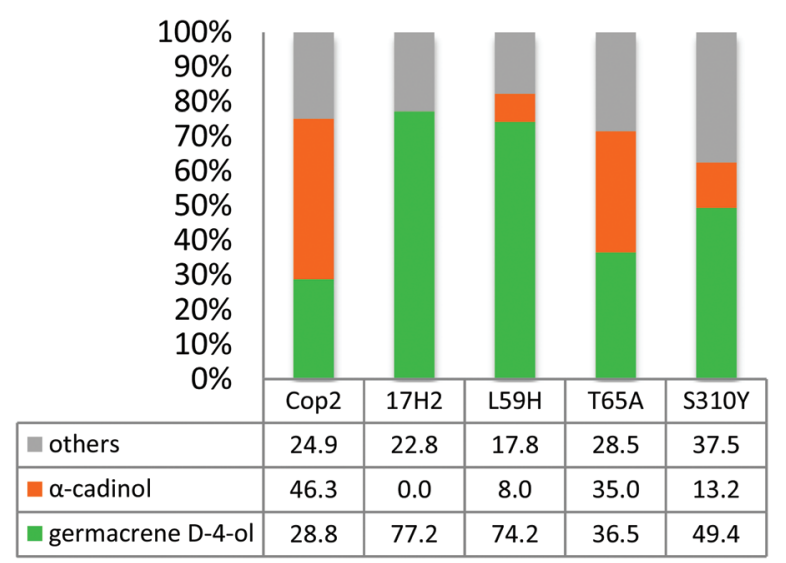

Fig. 1 Product distribution in \% of Cop2, the triple mutant $17 \mathrm{H} 2$ and the single mutants L59H, T65A and S310Y analyzed by GC-MS.

Table 1 Summary of the kinetic parameters of Cop2 and $17 \mathrm{H} 2$ with FPP

\begin{tabular}{llllllll}
\hline & \multicolumn{8}{c}{$\begin{array}{l}\text { Enzyme } \\
\text { concentration } \\
\text { Enzyme }\end{array}$} & $\begin{array}{l}K_{\mathrm{m}} \\
{[\mu \mathrm{M}]}\end{array}$ & $+/-$ & $\begin{array}{l}v_{\text {max }} \\
{\left[\mu \mathrm{M} \mathrm{h}^{-1}\right]} \\
{[\mu \mathrm{M}]}\end{array}$ & $\begin{array}{l}k_{\text {cat }} / K_{\mathrm{m}} \\
{\left[\mathrm{s}^{-1}\right]}\end{array}$ & $\begin{array}{l}{\left[\mathrm{mM}^{-1} \mathrm{~s}^{-1}\right]} \\
\text { Cop2 }\end{array} 2^{25.5}$ & 6.7 & 10.7 & 1.0 & 0.2 & 0.015 & 0.58 \\
$17 \mathrm{H} 2$ & 22.6 & 7.1 & 25.3 & 2.0 & 0.5 & 0.014 & 0.62
\end{tabular}

Because $17 \mathrm{H} 2$ contained three point mutations, we sought to elucidate whether one of the single point mutations caused the high selectivity or whether the combination of the three mutations was responsible for this effect. The three single mutants L59H, T65A and S310Y were therefore constructed, and the reactions of FPP catalyzed by these mutants were analyzed. 


Feature 1
1DGP_A
Cop2
1PS1_A
Feature 1
1DGP_A
Cop2
1PS1 A

\begin{abstract}
\# \#
4 PTQWSYLCHPRVKEVQDEVDGYFLENWKFPSFKAVRTFLdakFSEVTCLYF PLaIDDRTHFACRULTVLFL] DDVLE Im- 82

26 dCPF PLRVNPLCDEVGRLSEQWFLYYYOYYSPRAV-AFMaIKAGELTAACY PDAdAFHLRVSDDFMNFLFNF DDWLD If- 103

8 HIPLPGRQSPDHARAEAEQLAWPR I gIIRSDAAAERHLIGgYADLASRFY PHa TGADLDLGVDIMSWFFLF DDLFD ;pr 87
\end{abstract}

Fig. 2 Partial alignment of the amino acid sequences of Cop2 with other sesquiterpene synthases. The residues mutated in $17 \mathrm{H} 2$ are highlighted in green. The residues involved in substrate binding are marked in yellow. The blue boxes highlight the conserved aspartate rich motif and the N(S/T)(E/D) triad, necessary for the binding of $\mathrm{Mg}^{2+}$ ions. Cop2, 1DGP_A: aristolochene synthase from Penicillium roqueforti, 1PS1_A: pentalenene synthase.
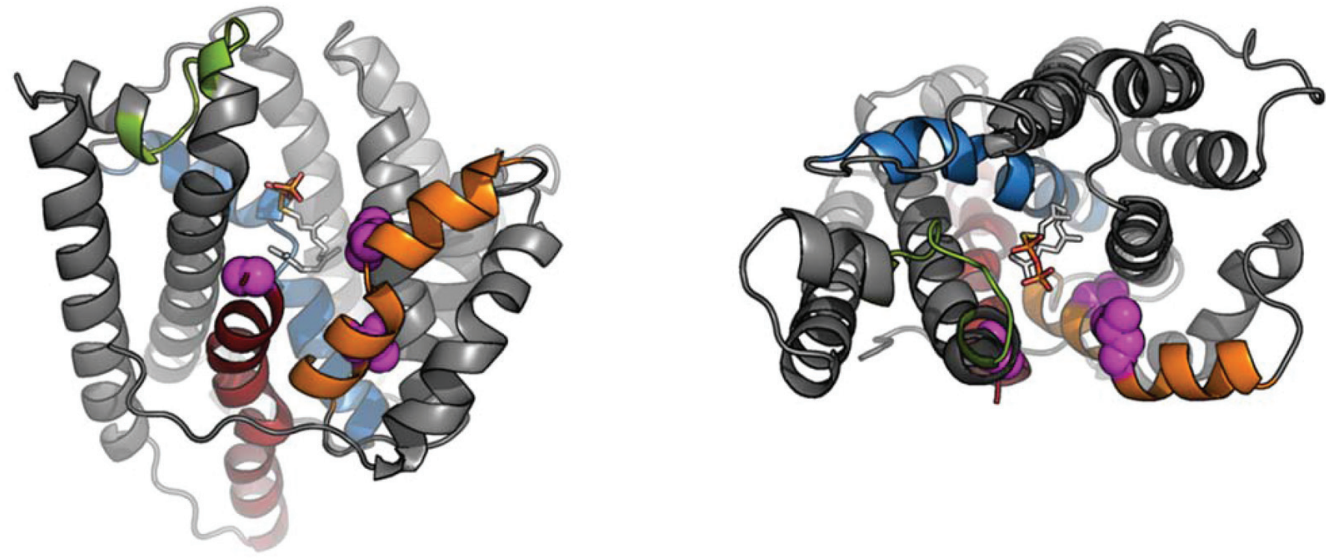

Fig. 3 Homology model of Cop2 based on the pentalenene synthase structure $1 \mathrm{HM} 7 .{ }^{15-17}$ The FFP analog from the structure $4 \mathrm{KUX}$ is shown in order to indicate the active site. The three residues mutated in 17H2 are shown in pink as follows: S310 is at the end of the J-helix (in red), L59 is in the upper portion of the C-helix (in orange) and T65 is in the lower portion of the C-helix. Also shown are the G-helix in light blue and the $\mathrm{H}$ - $\alpha 1$ loop in green. The image on the right is a view from the top.

Analysis of the three single mutants showed that, in comparison with Cop2, L59H and S310Y produce elevated germacrene D-4-ol amounts and reduced $\alpha$-cadinol amounts from FPP. The mutant T65A also showed a small improvement in germacrene D-4-ol selectivity. None of the single mutants completely abolished $\alpha$-cadinol production. These results are shown in Fig. 1 and suggest that a synergistic effect of the three mutations is responsible for the improvement in the product selectivity of $17 \mathrm{H} 2$ towards germacrene D-4-ol.

Though a triple mutant was identified from the Cop2 mutant library, any of the three single mutants would be found using our screening system, and the mutants all give comparable activities when measured with the assay (data not shown).

An alignment of Cop2 with aristolochene synthase and pentalenene synthase was constructed (Fig. 2). ${ }^{15-17}$ The structures and the corresponding active sites of aristolochene synthase and pentalenene synthase are known, ${ }^{16,17}$ and a comparison with Cop2 reveals that residues which are mutated in 17H2 (as highlighted in green) are directly adjacent to active site residues for T65 and S310, and five residues are removed from an active site residue in the case of L59. Despite L59 being the mutated residue furthest from the predicted active site cavity, it causes the largest change in product selectivity.
The locations of the mutations in $17 \mathrm{H} 2$ were further elucidated with a homology model of Cop2 built using SwissModel upon the crystal structure of the bacterial sesquiterpene synthase, pentalene synthase (Fig. 3). ${ }^{18}$ The two enzymes shared $21 \%$ sequence homology, and pentalene synthase had the highest homology to Cop2 of any terpene synthase crystal structures. The model shows that all three mutations are located near the active site yet do not line the active site cavity. Both L59H and T65A mutations are located within the C-helix (orange in Fig. 3), and the S301Y mutation is located at the end of the J-helix (red in Fig. 3). The location of these mutations is non-obvious - they would likely not be targeted for site-directed or site-saturation mutagenesis.

\section{Discussion}

Enzymatic terpene cyclization is initiated by the formation of a reactive carbocation. ${ }^{1-3}$ Class I enzymes, which include sesquiterpene synthases like Cop2, generate the carbocation by the release of the pyrophosphate $\left(\mathrm{PP}_{\mathrm{i}}\right)$ group of the substrate. Enzymes of this class contain characteristic DDxxD and NSE/ DTE motifs which facilitate the binding and subsequent cleavage of the $\mathrm{PP}_{\mathrm{i}}$ induced by three $\mathrm{Mg}^{2+}$ ions as cofactors. ${ }^{19-21}$ 
Additionally, a basic motif (RY) is also involved in the coordination of the $\mathrm{Mg}^{2+}$ and $\mathrm{PP}_{\mathrm{i}}$ complex. Mutation of the amino acids involved in $\mathrm{Mg}^{2+}$ and $\mathrm{PP}_{\mathrm{i}}$ binding generally results in severely attenuated enzyme activity. Mutations in this region in aristolochene synthase, for example, were reported to result in altered product distributions along with a 100-6500 fold decrease in the observed $k_{\text {cat }} / K_{\mathrm{m}}{ }^{6}$ Furthermore, mutations in the $\mathrm{Mg}^{2+}$ coordinating motifs of a fungal trichodiene synthase reduced kinetic parameters as well as product specificity. ${ }^{7}$ Consistent with these previous results, the present work identified no mutations in this area of the protein that maintained the activity.

Within the terpene synthase active site, amino acids (primarily aliphatic and aromatic) direct the propagation of the carbocation through complex reaction cascades. ${ }^{3,19,20}$ Additionally, reaction steps involving acid-base catalysis are thought to occur during sesquiterpene cyclization. The termination of the reaction cascade can occur either via a nucleophilic attack by water, leading to the formation of terpene alcohols or via proton abstraction to form double bonds. The active site of terpene synthases acts not only as a chaperone for the correct folding of the substrate but it also rearranges the carbocation and protects it from premature quenching by solvent molecules. Most previous mutational studies of sesquiterpene synthases have targeted residues within the active site.

Schmidt-Dannert and coworkers, for example, investigated the effects of mutation in the $\mathrm{H}-\alpha 1$ loop (which caps the active site) of several sesquiterpene synthases from Coprinus cinereus. ${ }^{9}$ These synthases include the $\alpha$-cuprenene synthase Cop6, and the multi-product terpene synthases Cop3 and Cop4. Though mutation of residues in the Cop $6 \mathrm{H}-\alpha 1$ loop caused little change in product selectivity, both Cop4 and Cop3 showed significant changes in product compositions upon mutation. The mutants were much less active than the parent enzymes with at least 3 -fold slower $k_{\text {cat }}$ values for Cop6 and two orders of magnitude slower $k_{\text {cat }}$ values for Cop4.

Weiss investigated the effects of structure guided mutations in tobacco epi-aristolochene synthase (TEAS). ${ }^{8}$ The crystal structure for this enzyme was previously solved, and the structure was used to introduce thermostabilizing mutations that were distant from the active site. Despite this distance, the thermostabilized mutant identified in this work suffered from losses in the product selectivity and activity.

Though some studies have indeed identified mutations that maintain or even improve the wild-type activity, these studies generally rely on structures and enzymes with close homologs. For example, Chen and Zhang solved the crystal structure of a bisabolene synthase, and used it to guide the mutation of the homolog amorphadiene synthase ( $82 \%$ amino acid identity). ${ }^{11}$ Mutation of T399 to serine increased the $k_{\text {cat }}$ of the enzyme two-fold without a decline in product selectivity. In another study, Noel and Chappell utilized the structure of TEAS to guide the inter-conversion of the product distribution of this enzyme and the close homolog henbane premnaspirodiene synthase (HPS) (72\% amino acid identity) without negatively affecting the activity. ${ }^{5}$
Keasling et al. used a humulene synthase homology model to identify active site residues. ${ }^{10}$ For each of 19 amino acids lining the active site, site-saturation mutagenesis was conducted to generate libraries of mutants. Six mutants containing up to 5 mutations each demonstrated impressive selectivities for products up to $85.7 \%$, and several of these mutants demonstrated the activity comparable to that of the parent. The method unfortunately required the extensive and tedious use of low-throughput GC-MS measurements. Keasling and co-workers conducted a separate study on the selective Gossypium arboreum (+)- $\delta$-cadinene synthase. ${ }^{4}$ Random mutagenesis by epPCR and a high-throughput solubility screen based on fusion to chloramphenicol acetyltransferase (CAT) were used to identify soluble mutants. From 1000 clones of the epPCR library, 100 mutants were re-screened for the activity by GC-MS, for each of two rounds of directed evolution. A total of 20 clones were identified that, in addition to the native product $(+)-\delta$-cadinene, also produced the new product germacrene D-4-ol. The best enzyme in this study was a double mutant that demonstrated 53\% selectivity for germacrene D-4-ol with only slight decreases in kinetic properties. ${ }^{22}$

The double mutant from Keasling's study and $17 \mathrm{H} 2$ from the current study both produce germacrene D-4-ol. ${ }^{4}$ Keasling's hypothesis for the increased production of germacrene D-4-ol was that the mutations they found allowed water into the active site. When water can reach the active site it leads to the termination of the reaction cascade by hydroxylation. In the absence of water, however, another cyclization occurs before the reaction is quenched.

In the case of Cop2, water quenching is responsible for formation of both of the major products $-\alpha$-cadinol and germacrene D-4-ol. This fact suggests that simple ingress of water into the active site is not responsible for the increase in selectivity for germacrene $\mathrm{D}-4-\mathrm{ol}$ mediated by $17 \mathrm{H} 2$. Instead, the three mutations may remove non-bonding interactions that would favor the second cyclization to form $\alpha$-cadinol.

Residues that cause an alteration of product selectivity upon mutation in sesquiterpene synthases have been called plasticity residues. ${ }^{10,11}$ The search for plasticity residues has primarily been limited to active site residues regardless of whether active site residues are ideal for this purpose. In Cop2, residues L59, T65, and S310 are not predicted to be active site residues, yet they are plasticity residues that alter product distributions and maintain the activity. The ideal plasticity residues may in fact be located remote from the active site, and this appears to be the case for Cop2. Further application of random mutagenesis and the high-throughput cyclization activity screen used here may reveal other instances of plasticity residues located in positions not currently amenable to structural prediction.

\section{Experimental}

\section{Instrumentation}

Gas chromatography (GC) was performed on a Shimadzu GC-17A instrument equipped with an FID detector. The 
column was an HP-5 column (Agilent, $30 \mathrm{~m} \times 0.32 \mathrm{~mm} \times$ $0.25 \mu \mathrm{m}$ film). For kinetic measurements, the temperature program was an initial temp of $90{ }^{\circ} \mathrm{C}$ for $1.0 \mathrm{~min}$, followed by a temp ramp of $9.0^{\circ} \mathrm{C} \mathrm{min}^{-1}$ to $174{ }^{\circ} \mathrm{C}$, followed by a ramp of $45^{\circ} \mathrm{C} \min ^{-1}$ to $260{ }^{\circ} \mathrm{C}$, and the temp was held at $260{ }^{\circ} \mathrm{C}$ for $2.0 \mathrm{~min}$. The split ratio was 1.0 , the column flow was $1.68 \mathrm{~mL}$ $\min ^{-1}$, the injector temp was $250{ }^{\circ} \mathrm{C}$, and the detector temp was $300^{\circ} \mathrm{C}$. Absorbance data from 96-well microtitre plates were collected on a Tecan Infinite ${ }^{\circledR}$ M200. Proteins were purified on an ÄKTAxpress with $1 \mathrm{~mL}$ HisTrap columns (GE Healthcare Life Sciences). GC-MS measurements were conducted on a Shimadzu GCMS-QP2010 SE instrument in electron ionization (EI) mode. The column used was a Shimadzu SHRXI-5MS $(30 \mathrm{~m} \times 0.25 \mathrm{~mm} \times 0.25 \mu \mathrm{m}$ film $)$. The temperature program was an initial temp of $75^{\circ} \mathrm{C}$ for $6.0 \mathrm{~min}$, followed by a temp ramp of $9.0^{\circ} \mathrm{C} \min ^{-1}$ to $180{ }^{\circ} \mathrm{C}$, followed by a temp ramp of $35{ }^{\circ} \mathrm{C} \mathrm{min}^{-1}$ to $280{ }^{\circ} \mathrm{C}$, and the temp was held at $280^{\circ} \mathrm{C}$ for $3.0 \mathrm{~min}$. The split ratio was 20 , the column flow was $1.5 \mathrm{~mL} \mathrm{~min}^{-1}$ and the injector temp was $250{ }^{\circ} \mathrm{C}$.

\section{General procedures}

Alcohol oxidase (AOX) was obtained from MP Biomedicals. Surrogate 1 (S1) was synthesized as described. ${ }^{13}$ Farnesyl diphosphate (FPP) was synthesized from farnesol according to the method of Poulter. ${ }^{23}$ Primers were purchased from Integrated DNA Technologies (IDT). E. cloni Express electrocompetent E. coli BL21 (DE3) was purchased from Lucigen. Alkaline phosphatase, Taq polymerase, T4 ligase, and restriction enzymes DpnI, XhoI, and NdeI were purchased from New England Biolabs (NEB). DNA sequencing was performed by Laragene (Culver City, CA, USA). TB refers to terrific broth from RPI, and LB refers to Luria broth from the same vendor. The Cop2 gene was a gift from Professor Claudia SchmidtDannert and was supplied as pUC-Cop2. The terpene synthase gene 03688 in pET-28a(+) was a gift from Professor David E. Cane. Standard buffer consisted of $50 \mathrm{mM}$ PIPES, $10 \mathrm{mM}$ $\mathrm{MgCl}_{2}, 100 \mathrm{mM} \mathrm{NaCl}$, and $2 \mathrm{mM}$ DTT at pH 7.6. Transfers of cultures and other liquids in 96-well format were done using a Hamilton Microlabs Nimbus Liquid Handling Robot.

\section{Cloning of Cop2 into pET-22b}

The gene for Cop2 was amplified from the vector pUC-Cop2 with the primers Cop2-for TTAACTTTAAGAAGGAGATATACATATGCACCACCACCACCACCACCCAAGTCCCGCGGGAGC and Cop2-rev GGGCTTTGTTAGCAGCCGGATCTCATTAGGCCAAAACCCGCACAGC using Phusion polymerase (NEB) with HF buffer and $60{ }^{\circ} \mathrm{C}$ as the annealing temperature. The part of the sequence that is homologous to the vector backbone is in italics; the start codon is underlined. The vector backbone was amplified from pET-22b using the primers pET22-for GCTTTGTTAGCAGCCGGATCTCA and pET22b-rev CCCCTCTAGAAATAATTTTGTTTAACTTTAAGAAGGAGATATACAT and the LongRange PCR Kit from Qiagen at the annealing temperature of $50{ }^{\circ} \mathrm{C}$. After separation on a $1 \%$ agarose gel the PCR products were excised and purified using the Zymoclean Gel DNA Recovery Kit (Zymo Research) following the procedures suggested by the manufacturer. $3 \mu \mathrm{L}$ of the gene and $2 \mu \mathrm{L}$ of the vector backbone were combined with $15 \mu \mathrm{L}$ of the mix described for the one-step isothermal DNA assembly by Gibson et $a .^{24}$ and the assembly was performed for $60 \mathrm{~min}$ at $50{ }^{\circ} \mathrm{C}$. An aliquot of $5 \mu \mathrm{L}$ of the resulting solution was transformed into chemically competent $E$. coli $\mathrm{DH} 5 \alpha$. After plasmid purification with the Zyppy ${ }^{\mathrm{TM}}$ Plasmid Miniprep Kit (Zymo Research), correct assembly was verified by sequencing (Laragen). However a point mutation resulting in a frame shift and premature abortion of the translation was identified. Therefore the gene sequence was fixed in a site-directed mutagenesis using the primers Cop2mt-for GACGAAATCATATTTTTCTCGATTCCTGAAGACCGCTG and Cop2mt-rev GAGAAAAATATGATTTCGTCATTAGTCCTGCGCGTTTATC and Phusion polymerase (NEB) with $\mathrm{HF}$ buffer and $60{ }^{\circ} \mathrm{C}$ as the annealing temperature. The base pair to be inserted is underlined. After digestion for 120 minutes at $37^{\circ} \mathrm{C}$ with DpnI (Neb) $5 \mu \mathrm{L}$ were transformed into chemically competent E. coli DH5 $\alpha$. After plasmid purification with the Zyppy ${ }^{\mathrm{TM}}$ Plasmid Miniprep Kit (Zymo Research) the success of the base insertion was verified by sequencing (Laragen). The plasmid was then transformed into BL21(DE3) for protein overexpression.

\section{Cop2 library formation}

A library of Cop2 mutants was produced through error-prone PCR using the primers pETCop2Fwd2 (AAAAAACCATATGCCAAGTCCCGCGGGAG) and pETCop2Rev2 (TTTTTTCTCGAGTTTAGGCCAAAACCCGCAC). The template was the Cop2 gene in pET-22b, using Taq (NEB) along with $200 \mu \mathrm{M}$ $\mathrm{MnCl}_{2}$ and $0.2 \mathrm{mM}$ of each dNTP (Roche). These conditions gave an approximate mutation rate of 1.4 base pairs per gene. The inserts produced by these epPCR reactions were double digested with XhoI and NdeI (NEB). A pET-28a(+) plasmid with a low-activity terpene synthase gene (sscg_03688, from Professor David E. Cane) was double digested with XhoI and NdeI (NEB) to remove the gene and then dephosphorylated using calf intestinal alkaline phosphatase (NEB). Both digestions were followed by gel purification and extraction using a kit (Promega) to produce purified DNA. The insert and backbone were ligated using $\mathrm{T} 4$ ligase (NEB) at $16^{\circ} \mathrm{C}$ overnight and the DNA was cleaned and concentrated using a kit (Zymo Research). Electro-competent BL21 (DE3) cells were transformed with $1 \mu \mathrm{L}$ of the cleaned ligation product and the resulting colonies were hand-picked individually into 96-well shallow plates ( $1 \mathrm{~mL}$ volume per well) using autoclaved toothpicks. The 96-well plates contained $300 \mu \mathrm{L}$ of LB media per well and $0.05 \mathrm{~g} \mathrm{~L}^{-1}$ of kanamycin. Cultures were grown overnight at $37{ }^{\circ} \mathrm{C}$ while shaking at $225 \mathrm{rpm}$ and $80 \% \mathrm{rh}$. Next, $50 \mu \mathrm{L}$ aliquots of the cultures were transferred into 96-well deep well plates ( $2 \mathrm{~mL}$ volume per well) containing $800 \mu \mathrm{L}$ of TB media as well as $0.05 \mathrm{~g} \mathrm{~L}^{-1}$ of kanamycin. Cryostocks of the libraries were made during transfer by transferring $120 \mu \mathrm{L}$ per well of the cultures to 96 -well microtiter plates in $20 \%$ glycerol. These cryostocks were flash-frozen on dry ice and stored in the $-80{ }^{\circ} \mathrm{C}$ freezer. The deep-well expression plate cultures were grown at $37{ }^{\circ} \mathrm{C}$ for $4 \mathrm{~h}$ shaking at $225 \mathrm{rpm}$ and $80 \%$ rh. Protein production 
was then induced by adding $50 \mu \mathrm{L}$ per well of IPTG in LB media for a total IPTG concentration of $0.5 \mathrm{mM}$. The plates were then returned to the shaker to sit at $25{ }^{\circ} \mathrm{C}$ with $225 \mathrm{rpm}$ and $0 \%$ rh for $24 \mathrm{~h}$. The cells were then pelleted by centrifugation at $3000 \mathrm{~g}$ for $10 \mathrm{~min}$ at $4{ }^{\circ} \mathrm{C}$. The plates containing the cell pellets were frozen at $-20{ }^{\circ} \mathrm{C}$ overnight until the screening protocol began.

\section{High-throughput screening}

Screening for all libraries and substrates was initiated by thawing deep well plates with cell pellets at room temperature for $30 \mathrm{~min}$. Then, to lyse the cells, $300 \mu \mathrm{L}$ of lysis buffer were added to each well. The lysis buffer consisted of Standard Buffer (pH 7.6, $50 \mathrm{mM}$ PIPES, $10 \mathrm{mM} \mathrm{MgCl}_{2}, 100 \mathrm{mM} \mathrm{NaCl}$, $2 \mathrm{mM}$ DTT) containing $10 \%$ betaine, $0.5 \mathrm{mg} \mathrm{mL}^{-1}$ lysozyme and $0.02 \mathrm{mg} \mathrm{mL}^{-1}$ DNAse I. The plates were vortexed to resuspend the pellets, and then were incubated at $37^{\circ} \mathrm{C}$ for $1 \mathrm{~h}$. Cell debris was pelleted by centrifugation at $5000 \mathrm{~g}$ at $4{ }^{\circ} \mathrm{C}$ for $15 \mathrm{~min}$. Using a liquid-handling robot, $100 \mu \mathrm{L}$ of the lysate from each well was transferred to 96-well microtiter plates, and then $100 \mu \mathrm{L}$ of $0.50 \mathrm{mM}$ S1 in Standard Buffer was added.

After the lysate and $\mathbf{S 1}$ were incubated for $1 \mathrm{~h}$ at $25{ }^{\circ} \mathrm{C}$, $10 \mu \mathrm{L}$ of alcohol oxidase $(50 \mu \mathrm{L}$ of AOX stock solution dissolved in $950 \mu \mathrm{L}$ of $0.1 \mathrm{M} \mathrm{KPi}, \mathrm{pH} 8.0$ ) were added to each well, and the plates were shaken on a table top orbital shaker at $600 \mathrm{rpm}$ for 10 minutes at room temperature. Next $16 \mu \mathrm{L}$ of $0.5 \mathrm{M}$ ethylenediaminetetraacetic acid (EDTA, pH 8.0) were added to each well, and the plates were shaken at $600 \mathrm{rpm}$ for $1 \mathrm{~min}$ at room temperature. Finally, $50 \mu \mathrm{L}$ of $0.16 \mathrm{M}$ Purpald ${ }^{\circledR}$ (SigmaAldrich) in $2 \mathrm{M} \mathrm{NaOH}$ was added to each well. The plates were shaken at $600 \mathrm{rpm}$ for $25 \mathrm{~min}$ at room temperature, after which a microtiter plate reader was used to record the absorbance of the wells at $550 \mathrm{~nm}$.

\section{Construction of the single mutants of $17 \mathrm{H} 2$ via fragment assembly PCR}

In order to analyze the three mutations of $17 \mathrm{H} 2$ individually, the corresponding single mutants L59H, T65A and S310Y were prepared. The forward and reverse primers with the respective mutations were designed and the PCR reactions were conducted with $65 \mathrm{ng}$ Cop2 DNA template, $0.5 \mu \mathrm{L}$ Phusion Polymerase, $1 \mu \mathrm{L}$ of forward and reverse primer $[10 \mu \mathrm{M}]$, HF buffer $5 \times$, and $1 \mu \mathrm{L}$ dNTPs [10 $\mathrm{mM}]$.

The following temperature program was used for the PCR for 30 cycles.

\begin{tabular}{ll}
\hline Temperature & Time \\
\hline $98{ }^{\circ} \mathrm{C}$ & $30 \mathrm{~s}$ \\
$98^{\circ} \mathrm{C}$ & $10 \mathrm{~s}$ \\
$58^{\circ} \mathrm{C}$ & $20 \mathrm{~s}$ \\
$72^{\circ} \mathrm{C}$ & $15 \mathrm{~s} / 1 \mathrm{~kb}$ \\
$72^{\circ} \mathrm{C}$ & $10 \mathrm{~min}$ \\
$10^{\circ} \mathrm{C}$ & Until end
\end{tabular}

The samples were loaded on a 1\% agarose gel and purified using the Promega Kit for DNA extraction and purification.

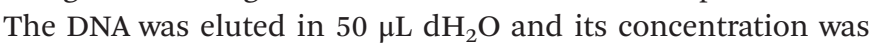

determined with a spectrophotometer (Nanodrop). The corresponding fragments were combined via fragment assembly PCR and the amount of the large and the small fragments was set according to their relative sizes. After 15 cycles with an extension time of $20 \mathrm{~s}$, the primers Cop2fwd2 and Cop2rev2 were added and another 20 cycles were started to amplify the full construct.

The following primers were used for the preparation of the single mutants of Cop2:

\begin{tabular}{ll}
\hline Primer & Nucleotide sequence \\
\hline pETCop2Fwd2 & AAAAAACCATATGCCAAGTCCCGCGGGAG \\
pETCop2Rev2 & TTTTTTCTCGAGTTTAGGCCAAAACCCGCAC \\
Cop2L59HrevCor & CTCGCCCGCTTTGTGTGCCATAAAC \\
Cop2L59Hfwd & GTTTATGGCACACAAAGCGGGCGAG \\
Cop2T65AfwdAg & CGAGCTCGCTGCTGCATGC \\
Cop2T65ArevAg & GCATGCAGCAGCGAGCTCG \\
Cop2S310Yfwd & GGGTCTCTAAATTGGTACATCGACGGGACA \\
Cop2S310Yrev & TGTCCCGTCGATGTACCAATTAGAGACCC
\end{tabular}

The DNA inserts were gel extracted and purified and $1 \mu \mathrm{g}$ DNA was digested with $1 \mu \mathrm{L}$ XhoI and $1 \mu \mathrm{L}$ NdeI for $1 \mathrm{~h}$ at $37{ }^{\circ} \mathrm{C}$. The same applies for the vector DNA. The pET28a $(+)$ vector backbone was cut with XhoI and NdeI for $1 \mathrm{~h}$ and dephosphorylated with $1 \mu \mathrm{L}$ alkaline phosphatase (Calf Intestine, NEB) for $30 \mathrm{~min}$.

\section{Ligation and transformation}

After another purification step by gel extraction, ligation of the cut insert $(10 \mu \mathrm{L})$ and the digested and dephosphorylated vector backbone $(2.5 \mu \mathrm{L})$ was performed with T4 DNA ligase $(1 \mu \mathrm{L})$ overnight at $16^{\circ} \mathrm{C}$. The ligation products were worked up with the DNA Clean \& Concentrator kit (Zymo Research) and eluted in $6 \mu \mathrm{L} \mathrm{dH_{2 }} \mathrm{O}$. For the transformation $1 \mu \mathrm{L}$ of the concentrated ligation product was added to $50 \mu \mathrm{L}$ of electrocompetent E. coli BL21 (DE3) cells. The cells were transferred into a cooled electroporation cuvette and pulsed with a voltage of $2.5 \mathrm{kV}$. Immediately afterwards $950 \mu \mathrm{L}$ of SOC media was added and the cells were incubated for $1 \mathrm{~h}$ at $37^{\circ} \mathrm{C}$ and 225 rpm. After recovery $30 \mu \mathrm{L}$ and $200 \mu \mathrm{L}$ of the cell suspension were plated on $\mathrm{LB}_{\mathrm{Kan}}$ agar plates with a kanamycin sulfate concentration of $50 \mathrm{mg} \mathrm{L}^{-1}$. The plates were incubated overnight at $37^{\circ} \mathrm{C}$.

In order to identify positive clones, overnight cultures were prepared and Minipreps were prepared with the QIAprep Spin Miniprep Kit and sent for sequencing to Laragen with the primers T7 Promoter and T7 Terminator. Glycerol stocks with a final glycerol concentration of $20 \%$ were prepared from clones with the correct sequences, frozen on dry ice and stored at $-80{ }^{\circ} \mathrm{C}$.

\section{Cultivation and protein expression}

The proteins were overexpressed in $E$. coli BL21. Two overnight cultures were prepared from the strain of interest by inoculating $5 \mathrm{~mL}$ of $\mathrm{LB}_{\mathrm{Kan}}$ medium with cells from a cryostock or from a plate. The cultures were grown at $37{ }^{\circ} \mathrm{C}$ and $225 \mathrm{rpm}$ 
overnight. For the main cultures, $1 \mathrm{~L}$ TB media was prepared in $2 \mathrm{~L}$ Erlenmeyer flasks and autoclaved before the antibiotic kanamycin sulfate was added to a final concentration of $50 \mathrm{mg}$ $\mathrm{L}^{-1}$. The $\mathrm{TB}_{\text {Kan }}$ media were inoculated with the overnight cultures and incubated at $37^{\circ} \mathrm{C}$ and $200 \mathrm{rpm}$. The ODs at $600 \mathrm{~nm}$ were measured with a spectrophotometer. After $\sim 3-4 \mathrm{~h} \mathrm{OD}_{600} \mathrm{~s}$ of 0.5-1.0 were obtained and protein expression was induced by the addition of IPTG to an end concentration of $0.5 \mathrm{mM}(0.12 \mathrm{~g}$ IPTG

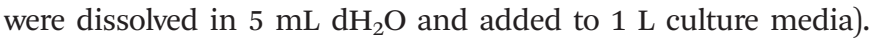
After the induction, the temperature was decreased to $25{ }^{\circ} \mathrm{C}$ and the cultures were incubated for another $24 \mathrm{~h}$ at $200 \mathrm{rpm}$. Then the cells were harvested by centrifugation at $4000 \mathrm{~g}$ and $4{ }^{\circ} \mathrm{C}$ for $15 \mathrm{~min}$. The pellets were resuspended in $\sim 20 \mathrm{~mL}$ Buffer A (pH 7.0, $50 \mathrm{mM}$ Tris/HCl, $5 \mathrm{mM} \mathrm{MgCl}_{2}, 300 \mathrm{mM} \mathrm{NaCl}, 2 \mathrm{mM}$ DTT, $10 \%(\mathrm{v} / \mathrm{v})$ glycerol, $10 \mathrm{mM}$ imidazole for Buffer $\mathrm{A}$ and $500 \mathrm{mM}$ for Buffer B) and frozen at $-20^{\circ} \mathrm{C}$.

\section{Protein purification}

After thawing the cell pellets, the lysis of the resuspended cells was performed by ultrasonication for $2 \mathrm{~min}$ (pulse on $5 \mathrm{~s}$, pulse off $5 \mathrm{~s}$ ). The cell lysates were constantly kept on ice and after sonication they were centrifuged at $20000 \mathrm{~g}$ for $30 \mathrm{~min}$ at $4{ }^{\circ} \mathrm{C}$. The supernatants were filtered through $0.2 \mu \mathrm{m}$ cellulose filters and if necessary $0.02 \mathrm{mg} \mathrm{mL}^{-1}$ DNAse was added. The purification of the proteins was performed with an ÄKTAxpress system from GE Healthcare. Since the proteins were hexahistidine-tagged, $1 \mathrm{~mL}$ HisTrap Ni-NTA columns were used for the purification and an imidazole gradient was applied for elution of the protein using Buffers A and B above. The fractions containing proteins were identified by monitoring the absorbance at $280 \mathrm{~nm}$, and then pooled. The buffer was exchanged with Standard Buffer containing $10 \%$ betaine (w/v) using Amicon ${ }^{\circledR}$ Ultra-15 Ultracel ${ }^{\circledR}$ cellulose 10000 MW-cutoff centrifugal filters. The purified proteins were aliquoted and stored at $-80{ }^{\circ} \mathrm{C}$ until they were further used. The protein concentration was determined by measuring the absorbance at $280 \mathrm{~nm}$. Therefore the protein was denatured in $500 \mu \mathrm{L} 6 \mathrm{M}$ guanidinium chloride and the average of three different measurements was calculated. To check the purity and molecular weights of the proteins, SDS-PAGE analysis was performed.

\section{GC-MS analysis}

To test the conversion of the natural substrate FPP, GC-scale reactions were performed at an enzyme concentration of $2 \mu \mathrm{M}$ and a substrate concentration of $300 \mu \mathrm{M}$. The reactions were performed in $2 \mathrm{~mL}$ GC vials in a total reaction volume of $500 \mu \mathrm{L}$. First, Standard Buffer containing 10\% betaine was added to the vials. The enzyme and substrate were added and the reactions were overlaid with $500 \mu \mathrm{L}$ hexanes containing $200 \mu \mathrm{M}$ dodecane as the internal standard $(4.6 \mu \mathrm{L}$ dodecane per $100 \mathrm{~mL}$ hexanes). The samples were closed with a septum cap and in the case of Cop2 they were incubated at $30^{\circ} \mathrm{C}$ for $2 \mathrm{~h}$. The incubation time and temperature were chosen depending on the current enzyme and experiment. Afterwards the reactions were stopped by adding $40 \mu \mathrm{L}$ of EDTA (0.5 M, $\mathrm{pH} 8$ ) and vortexing. Sodium sulfate was added to glass pip- ettes that were stuffed with small pieces of Kimwipes ${ }^{\mathrm{TM}}$ tissue and $250 \mu \mathrm{L}$ of the organic layer were then filtered through the sodium sulfate. The filtrates were collected in a GC vial with a low-volume insert and used for GC-MS analysis. Relative quantifications were performed using ion abundances. ${ }^{4}$ Reactions were run in triplicate.

\section{Kinetic measurements}

In order to estimate the kinetic parameters of the parent Cop2 and the triple mutant $17 \mathrm{H} 2$, GC-scale reactions were conducted as above with different substrate concentrations. All reactions were performed in $2 \mathrm{~mL}$ GC vials in $500 \mu \mathrm{L}$ Standard Buffer with $10 \%$ betaine. In the case of the wild type Cop2, an enzyme concentration of $0.2 \mu \mathrm{M}$ was used, whereas for the mutant $17 \mathrm{H} 2$ a concentration of $0.5 \mu \mathrm{M}$ was used. FPP concentrations from 6.25 to $100 \mu \mathrm{M}$ and from 10 to $200 \mu \mathrm{M}$ were used for the wild type and mutant enzymes, respectively. All samples were closed with a septum cap and incubated at room temperature. The reactions were stopped after 5, 10, 15, 20, 30, 40,50 and $60 \mathrm{~min}$ by the addition of $40 \mu \mathrm{L}$ of EDTA $(0.5 \mathrm{M}, \mathrm{pH}$ 8) and vortexing. The organic layer was filtered through sodium sulfate as described above and used for GC measurements. Double determination was made for all samples. The curve fitting was done with Prism. The same results were obtained with the program Mathematica. The product formation increased linearly for the first 30-40 min. The peak areas were converted into the estimated product concentrations with the help of the internal standard dodecane at a known concentration of $200 \mu \mathrm{M}$. Therefore, the products are quantified as dodecane equivalent $\mu \mathrm{M}$ units. Though this method is only for estimation of product concentrations, the use of the same comparison for both Cop2 and $17 \mathrm{H} 2$ gives a useful approximation of relative kinetic behavior.

\section{Identification of germacrene D-4-ol and $\alpha$-cadinol}

Compounds were identified by comparison of their retention time, mass fragmentation patterns, and Kovat's indices with the known values. Fragmentation patterns were searched for similarity in the NIST library in the Shimadzu 2010 GC-MS software. Kovat's indices were determined by running a standard sample containing linear alkanes from C10 to C16. Germacrene D-4-ol was readily determined using these methods. The retention times and fragmentation patterns of $\alpha$-cadinol, however, are quite similar to other diastereomers. To aid in product identification, T-muurolol synthase sscg_03688 was expressed in E. coli containing the gene in pET-28a(+) as provided by David E. Cane. ${ }^{25}$ The enzyme was purified as described in the literature. ${ }^{25}$ GC-scale reactions were conducted using $2 \mu \mathrm{M}$ of enzyme for Cop2, 17H2, and sscg_03688 and $300 \mu \mathrm{L}$ of FPP. Cop 2 and $17 \mathrm{H} 2$ reactions were run in standard buffer with $10 \% \mathrm{w} / \mathrm{v}$ betaine. The sscg_03688 reaction was run in standard buffer with $20 \%$ glycerol. The reactions were incubated overnight at room temperature and worked up and analyzed by GC-MS as described above. Analysis of the product by GC-MS showed that the product from Cop2 had a slightly longer retention time than T-muurolol, and a similar 
mass spectral fragmentation pattern, and was therefore identified as $\alpha$-cadinol. ${ }^{26-33}$

\section{Conclusions}

In this study, a multi-product terpene synthase, Cop2, was converted to a more selective mutant by random mutagenesis. The results suggest that random mutagenesis and screening combined with an assay for the cyclization activity may be an effective strategy to identify residues that influence the product selectivity without imposing activity penalties. No structural information was used to guide the introduction of mutations, and the mutations were found at residues that would be nonobvious targets for mutagenesis in structure-based approaches.

\section{Acknowledgements}

We are grateful to Frances H. Arnold, Claudia SchmidtDannert, David Cane, Scott Virgil, Robert M. Coates, and David Christianson for their pioneering studies, invaluable advice, encouragement, and materials. We thank Sabine BrinkmannChen, John McIntosh, Thomas Heel, and Chris Farwell for advice and assistance. RL acknowledges the support of the NIH fellowship 1F32GM095061. The content is solely the responsibility of the authors and does not necessarily represent the official views of the NIH. KSR thanks the Deutscher Akademischer Austauschdienst (DAAD) for a postdoctoral fellowship. KZK and RZK acknowledge the support of Summer Undergraduate Research Fellowships from the California Institute of Technology.

\section{References}

1 E. Breitmaier, Terpenes; Flavors, Fragrances, Pharmaca, Pheromones, Wiley-VCH, Weinheim, 2006.

2 J. S. Dickschat, Nat. Prod. Rep., 2011, 28, 1917.

3 R. K. Allemann, Pure Appl. Chem., 2008, 80, 1791.

4 Y. Yoshikuni, V. J. Martin, T. E. Ferrin and J. D. Keasling, Chem. Biol., 2006, 13, 91.

5 B. T. Greenhagen, P. E. O'Maille, J. P. Noel and J. Chappell, Proc. Natl. Acad. Sci. U. S. A., 2006, 103, 9826.

6 B. Felicetti and D. E. Cane, J. Am. Chem. Soc., 2004, 126, 7212.

7 L. S. Vedula, J. Jiang, T. Zakharian, D. E. Cane and D. W. Christianson, Arch. Biochem. Biophys., 2008, 469, 184.

8 J. E. Diaz, C.-S. Lin, K. Kunishiro, B. K. Feld, S. K. Avrantinis, J. Bronson, J. Greaves, J. G. Saven and G. A. Weiss, Protein Sci., 2011, 20, 1597.

9 F. Lopez-Gallego, G. T. Wawrzyn and C. Schmidt-Dannert, Appl. Environ. Microbiol., 2010, 76, 7723.

10 Y. Yoshikuni, T. E. Ferrin and J. D. Keasling, Nature, 2006, 440, 1078.

11 J.-X. Li, X. Fang, Q. Zhao, J.-X. Ruan, C.-Q. Yang, L.-J. Wang, D. J. Miller, J. A. Faraldos, R. K. Allemann, X.-Y. Chen and P. Zhang, Biochem. J., 2013, 451, 417.
12 D. B. Little and R. B. Croteau, Arch. Biochem. Biophys., 2002, 402, 120.

13 R. Lauchli, K. S. Rabe, K. Z. Kalbarczyk, A. Tata, T. Heel, R. Z. Kitto and F. H. Arnold, Angew. Chem., Int. Ed., 2013, 52, 5571.

14 S. Agger, F. Lopez-Gallego and C. Schmidt-Dannert, Mol. Microbiol., 2009, 72, 1181.

15 A. Marchler-Bauer, C. Zheng, F. Chitsaz, M. K. Derbyshire, L. Y. Geer, R. C. Geer, N. R. Gonzales, M. Gwadz, D. I. Hurwitz, C. J. Lanczycki, F. Lu, S. Lu, G. H. Marchler, J. S. Song, N. Thanki, R. A. Yamashita, D. Zhang and S. H. Bryant, Nucleic Acids Res., 2013, 41, D348.

16 J. M. Caruthers, I. Kang, M. J. Rynkiewicz, D. E. Cane and D. W. Christianson, J. Biol. Chem., 2000, 275, 25533.

17 C. A. Lesburg, G. Zhai, D. E. Cane and D. W. Christianson, Science, 1997, 277, 1820.

18 SWISS-MODEL, Protein Structure Bioinformatics group at the Swiss Institute of Bioinformatics and the Biozentrum University of Basel http://swissmodel.expasy.org/.

19 Y. Gao, R. B. Honzatko and R. J. Peters, Nat. Prod. Rep., 2012, 29, 1153.

20 D. W. Christianson, Chem. Rev., 2006, 106, 3412.

21 D. J. Miller and R. K. Allemann, Nat. Prod. Rep., 2012, 29, 60 .

22 Keasling reports higher selectivity and productivity when no organic overlayer is used to sequester products. We do not use these data for comparison because the more volatile $(+)$ - $\delta$-cadinene is removed into the vapor phase and thereby biases both the selectivity and productivity in favor of germacrene D-4-ol.

23 V. J. Davisson, A. B. Woodside, T. R. Neal, K. E. Stremler, M. Muehlbacher and C. D. Poulter, J. Org. Chem., 2006, 5, 4768.

24 D. G. Gibson, L. Young, R. Y. Chuang, J. C. Venter, C. A. Hutchison III and H. O. Smith, Nat. Methods, 2009, 6, 343.

25 Y. Hu, W. K. W. Chou, R. Hopson and D. E. Cane, Chem. Biol., 2011, 18, 32.

26 B. Pickel, D. P. Drew, T. Manczak, C. Weitzel, H. T. Simonsen and D.-K. Ro, Biochem. J., 2012, 448, 261.

27 M. Hazzit, A. Baaliouamer, M. L. Faleiro and M. G. Miguel, J. Agric. Food Chem., 2006, 54, 6314.

28 M. Jalali-Heravi, B. Zekavat and H. Sereshti, J. Chromatogr. A, 2006, 1114, 154.

29 W. A. Asuming, P. S. Beauchamp, J. T. Descalzo, B. C. Dev, V. Dev, S. Frost and C. W. Ma, Biochem. Syst. Ecol., 2005, 33, 17.

30 R. Baranauskiene, P. R. Venskutonis, P. Viskelis and E. Dambrauskiene, J. Agric. Food Chem., 2003, 51, 7751.

31 G. Gkinis, O. Tzakou, D. Iliopoulou and V. Roussis, Z. Naturforsch., C: Biosci., 2003, 58, 681.

32 V. Roussis, M. Tsoukatou, P. V. Petrakis, I. Chinou, M. Skoula and J. B. Harborne, Biochem. Syst. Ecol., 2000, 28, 163.

33 J. P. Mevy, A. Bousquet-Melou, S. Greff, J. Millogo and C. Fernandez, Biochem. Syst. Ecol., 2006, 34, 815. 